Arq. Bras. Med. Vet. Zootec., v.69, n.1, p.106-110, 2017

\title{
Cisto ósseo aneurismático em tecido mole em um cão - relato de caso
}

\author{
[Aneurysmal bone cyst in soft tissue in a dog-Case Report] \\ B.S. Barni ${ }^{1}$, E.R. Santos ${ }^{1}$, N.S. Rosa ${ }^{1}$, D.J. Lopes ${ }^{1}$, K.L. Hesse ${ }^{1}$, \\ S.P. Pavarini ${ }^{2}$, E.A. Contesini ${ }^{2}$ \\ ${ }^{1}$ Residente - Faculdade de Veterinária - Universidade Federal do Rio Grande do Sul - Porto Alegre, RS \\ ${ }^{2}$ Faculdade de Veterinária - Universidade Federal do Rio Grande do Sul - Porto Alegre, RS
}

\begin{abstract}
RESUMO
Este trabalho descreve o diagnóstico e o tratamento instituído para um cão com um raro cisto ósseo aneurismático originado em tecido mole. O paciente foi apresentado para atendimento no Hospital de Clínicas Veterinárias da Universidade Federal do Rio Grande do Sul devido à dificuldade de locomoção, fraqueza nos membros pélvicos e disquesia havia 15 dias. Já estava recebendo tratamento medicamentoso sem sucesso. Ao exame clínico, notou-se aumento de volume sólido na região perineal direita, e foram solicitados exames complementares de imagem. A radiografia da região sugeriu hérnia perineal direita ou neoplasia. O cão foi encaminhado para cirurgia, na qual foi removida uma estrutura tumoral, arredondada, de aspecto ossificado. O exame histopatológico diagnosticou a estrutura como um cisto ósseo aneurismático em tecido mole, e o paciente recuperou-se totalmente após a excisão cirúrgica.
\end{abstract}

Palavras-chave: canino, tumor benigno, períneo

\begin{abstract}
This paper describes the diagnosis and treatment of a dog with a rare aneurysmal bone cyst in soft tissue. The patient was attended in the Veterinary Clinic Hospital at the Fedral University of Rio Grande do Sul due to limited mobility, weakness in hind limbs, and dyschezia for 15 days. It was already receiving medical treatment without success. Upon clinical examination a solid increase volume in the right perineal region was detected, and complementary imaging tests were requested. Radiography of the region suggested right perineal hernia or neoplasia. The dog was submitted to surgery, and a rounded and ossified tumoral structure was removed. The histopathological exam diagnosed the structure as an aneurysmal bone cyst in soft tissue, and the patient recovered fully after surgical excision.
\end{abstract}

Keywords:canine, benign tumor, perineum

\section{INTRODUÇÃO}

O cisto ósseo aneurismático é uma lesão benigna, de caráter expansivo e localmente destrutivo, porém não neoplásico, que ocorre normalmente em ossos longos e vértebras (Asaumi et al., 2003). Sua incidência é rara em animais, com poucos relatos em cães, gatos e cavalos (Biller et al., 1987).

Os sinais clínicos estão relacionados à sensação dolorosa e à claudicação, dependendo de sua localização (Sarierler et al., 2004; Vignoli et al.,

Recebido em 4 de dezembro de 2015

Aceito em 12 de maio de 2016

E-mail: brunnabarni@hotmail.com
2015), além do aumento de volume no local da lesão (Dowdle et al., 2003). Muitas vezes há sinais secundários, como fraqueza muscular, relacionados à compressão das estruturas adjacentes, tendo em vista que normalmente se desenvolve a partir de um osso (Nomura e Sato, 1997).

Em cães, nos escassos casos de cistos ósseos aneurismáticos relatados, a lesão localizava-se no úmero (Sarieler et al., 2004), na ulna (Barnhart, 2002; Vignoli et al., 2015), na tíbia (Duval et al., 1995), no púbis (Nomura e Sato, 1997) e no osso peniano (Verão et al., 2010), e os sinais clínicos 
estavam relacionados também à compressão de estruturas próximas ao cisto.

O desenvolvimento do cisto ósseo aneurismático em tecidos moles é bastante incomum, sem relatos em animais na literatura consultada. É uma lesão tumoriforme de característica benigna, que pode ser tratada pela simples excisão, mas deve ser distinguida de uma variedade de outros processos neoplásicos (Nielsen et al., 2002).

Diante dos raros casos descritos sobre esse tema em medicina veterinária, o objetivo deste trabalho é descrever o diagnóstico e o tratamento instituído para um cão com cisto ósseo aneurismático originado em tecido mole.

\section{CASUÍSTICA}

Um canino, macho, da raça Pointer, pesando $36 \mathrm{~kg}$, com nove anos de idade, não castrado, foi atendido com queixa principal de dificuldade de locomoção e fraqueza nos membros pélvicos. Por cerca de 15 dias, o cão apresentava dificuldade para se levantar e disquesia. O paciente já estava em tratamento clínico havia sete dias, prescrito por outro médico veterinário, recebendo pela via oral carprofeno $\left(2,2 \mathrm{mg} \cdot \mathrm{kg}^{-1}\right.$, BID), lactulose $\left(0,5 \mathrm{ml} . \mathrm{kg}^{-1}\right.$, BID) e sulfato de condroitina (20mg. $\mathrm{kg}^{-1}$, SID).

No exame clínico, o cão apresentava-se com frequência cardíaca de 100 batimentos por minuto, frequência respiratória de 24 movimentos por minuto, linfonodos não reativos, temperatura retal de $38,0^{\circ} \mathrm{C}$, normo-hidratado e normocorado. As únicas alterações apresentadas foram sensibilidade à palpação da região coxofemoral e aumento de volume de consistência firme na região perineal direita. Foram solicitados exames complementares de imagem. $\mathrm{Na}$ ultrassonografia abdominal, não foram detectadas alterações nos órgãos avaliados, tampouco foi sugerida hérnia perineal. Radiografias da região coxofemoral evidenciaram espondiloartrose em coluna vertebral lombossacra, engrossamento do colo do fêmur esquerdo, esclerose em borda acetabular esquerda e massa radiopaca em tecidos moles na topografia perineal direita (sugestivo de hérnia perineal ou neoplasia) (Fig. 1).

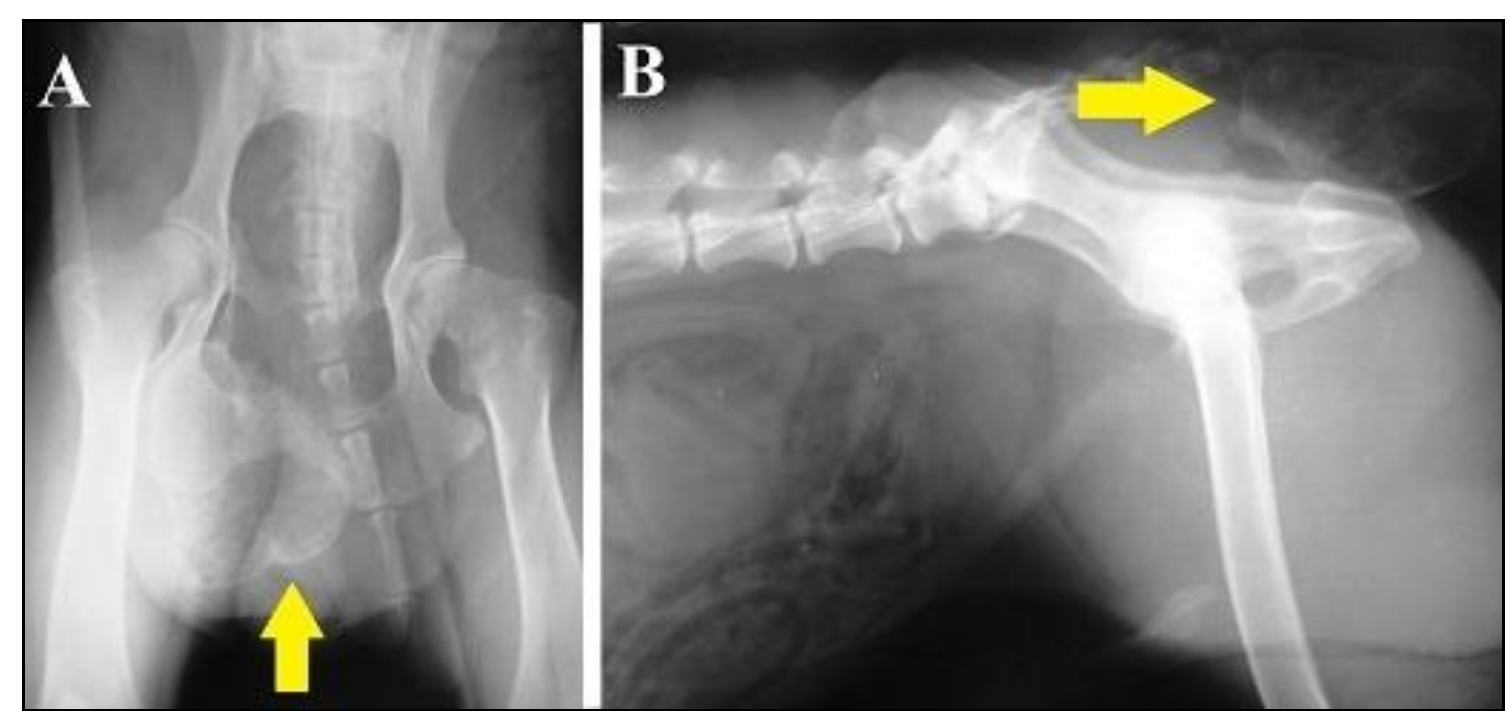

Figura 1. Cisto ósseo aneurismático em tecido mole em um cão. Radiografia coxofemoral ventrodorsal (A) e laterolateral (B), evidenciando presença de massa radiopaca em tecidos moles na topografia perineal direita (setas).

O paciente foi encaminhado para a cirurgia, após se verificarem os resultados de exames sanguíneos solicitados (hemograma, plaquetas, albumina, creatinina, ureia, alanino aminotransferase e fosfatase alcalina), que estavam todos dentro dos parâmetros fisiológicos para a espécie.

Como medicação pré-anestésica, utilizou-se meperidina intramuscular $\left(2 \mathrm{mg} \cdot \mathrm{kg}^{-1}\right)$. O paciente 
foi induzido à anestesia geral com propofol intravenoso $\left(4 \mathrm{mg} \mathrm{kg}^{-1}\right)$, seguido de intubação orotraqueal, recebendo oxigênio $100 \%$ durante todo o procedimento. A manutenção anestésica foi realizada com isoflurano ao efeito em sistema de anestesia semifechado. Com o paciente em plano anestésico adequado, procedeu-se inicialmente à orquiectomia, pela técnica aberta, como de rotina. O canino foi, então, posicionado em decúbito ventral, com a pelve elevada e os membros pélvicos sobre a extremidade da mesa (acolchoada). A pele foi incisada na região perineal direita e o tecido subcutâneo foi afastado. Logo se percebeu que o aumento de volume se referia a uma estrutura tumoral arredondada com consistência ossificada. A estrutura foi divulsionada em todos os seus limites, com certa dificuldade devido ao acesso, permanecendo a região mais cranial presa aos tecidos moles, a qual foi removida por tração manual. Com a massa tumoral removida, verificou-se a ausência de hérnia na região, e o tecido muscular foi aproximado com fio poliglecaprone 25 (2-0), no padrão isolado simples (PIS). O subcutâneo foi reduzido com o mesmo fio, no padrão contínuo simples, e a pele suturada com náilon 3-0 (PIS). O paciente recebeu alta ao fim do procedimento, e o material retirado foi enviado para exame histopatológico.
Após 11 meses do procedimento cirúrgico, em um contato com o tutor, este relatou que o cão não apresentava qualquer sinal de recidiva do tumor, mantendo-se ativo, sem dificuldade locomotora ou para se levantar.

$\mathrm{Na}$ análise macroscópica, a espécime era uma massa de consistência dura, medindo $8,5 \mathrm{~cm} \mathrm{x}$

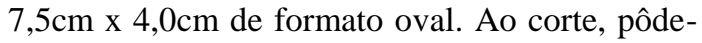
se observar que esta era composta por uma superfície delgada de aspecto ósseo, por vezes formando septos de espessuras variadas e de aspecto hemorrágico. No centro da lesão, visualizava-se uma área cística, que estava preenchida por líquido avermelhado (Fig. 2). Microscopicamente, tratava-se de uma estrutura cística com cápsula formada por tecido ósseo trabecular, entremeada por múltiplas estruturas vasculares repletas de sangue, além de moderada quantidade de tecido conjuntivo arranjado de maneira frouxa. Havia, ainda, moderada quantidade de macrófagos carregados de hemossiderina e áreas multifocais com osteoclastos, frequentemente multinucleados (Fig. 3). O resultado da análise patológica foi compatível com cisto ósseo aneurismático em tecido mole.

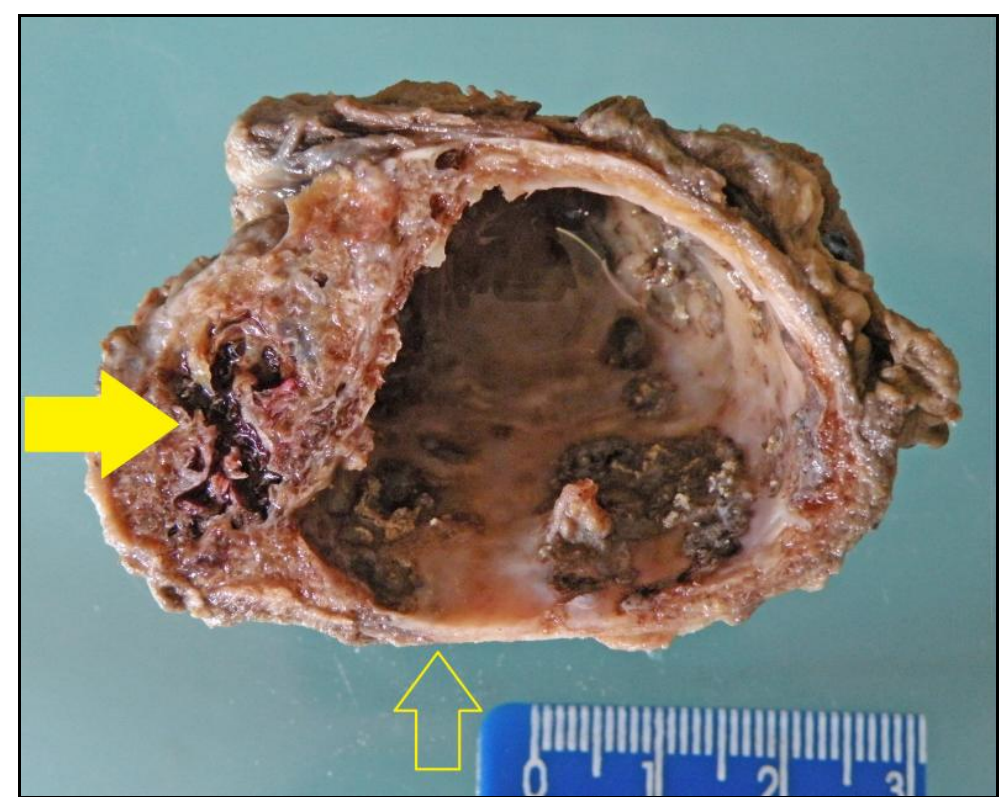

Figura 2. Cisto ósseo aneurismático em tecido mole em um cão. Material formolizado. Estrutura cística, com formato ovalado, composta por fina cápsula de tecido ósseo (seta vazia), por vezes formando septos de aspecto hemorrágico (seta cheia). 


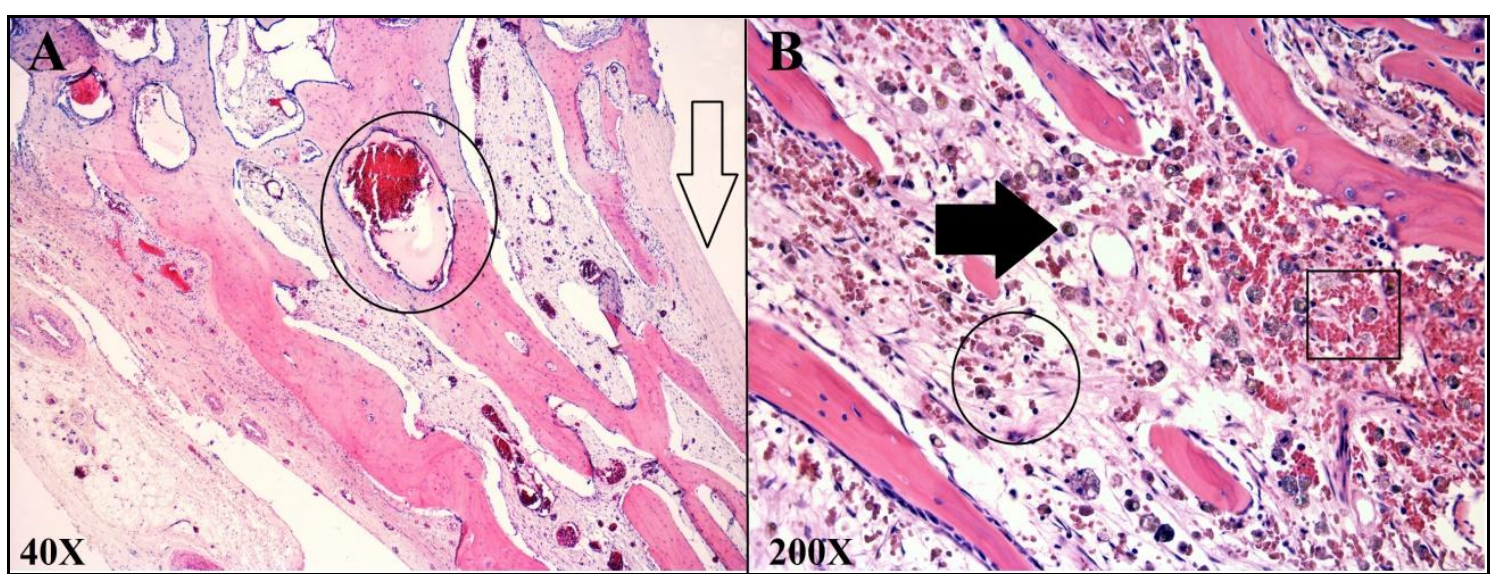

Figura 3. Aspecto histológico de um cisto ósseo aneurismático em tecido mole em um cão. A: parede do cisto composta por tecido ósseo de aspecto trabecular envolto por tecido conjuntivo fibroso (seta vazia) e formações vasculares (círculo). 40x, HE. B: moderada quantidade de tecido conjuntivo arranjado de maneira frouxa entre trabéculas ósseas (círculo), além de hemorragia (quadrado) e inúmeros macrófagos contendo hemossiderina em seu citoplasma (seta cheia). 200x, HE.

\section{DISCUSSÃO}

O diagnóstico de cisto ósseo aneurismático em tecido mole no canino deste relato baseou-se nos achados clínicos, radiográficos e patológicos. Histologicamente, a lesão era idêntica à descrita em cães com cisto ósseo aneurismático em ossos e em humanos com a forma que ocorre em tecido mole, caracterizada por uma lesão expansiva, de aspecto cístico, repleta de sangue e com paredes formadas por trabéculas ósseas entremeadas por tecido conjuntivo e neoformações vasculares (Nomura e Sato, 1997; Nielsen et al., 2002; Verão et al., 2010).

A etiologia da lesão não ficou clara neste caso, porém, até mesmo na literatura consultada, a patogênese do cisto ósseo aneurismático é controversa. Diversos autores consultados por Silva et al. (2007) concordaram que o cisto resulta de um distúrbio hemodinâmico do osso, na forma de uma oclusão venosa súbita ou do desenvolvimento de um distúrbio arteriovenoso. Os mesmos autores citaram que o trauma também foi proposto como etiologia, mas com poucas evidências. Torna-se mais difícil ainda pontuar a origem do cisto ósseo aneurismático deste relato, tendo em vista a sua localização nos tecidos moles.

Os principais sinais clínicos observados pelo tutor no paciente relatado foram dificuldade locomotora, com fraqueza nos membros pélvicos, associada à disquesia. Esses sinais provavelmente estavam relacionados à dor e à compressão que ocorriam na região onde o cisto se encontrava, corroborando os dados da literatura pesquisada (Verão et al., 2010). Apesar de o cisto relatado localizar-se em tecido mole, também levou à dificuldade de eliminar as fezes, pela proximidade do reto, assim como relataram Nomura e Sato (1997) em um cão no qual o cisto se originava do púbis.

A radiografia da região coxofemoral evidenciou massa radiopaca em tecidos moles, concordando com o aspecto das imagens radiográficas dos cistos ósseos aneurismáticos diagnosticados por Sarierler et al. (2004) e Verão et al. (2010), em úmero e pênis de cão. No presente relato, não se realizou tomografia computadorizada, método utilizado para diagnóstico complementar de cistos ósseos aneurismáticos (Sarierler et al., 2004).

O tratamento empregado no cão deste caso foi a exérese cirúrgica do cisto ósseo aneurismático, assim como relataram Nielsen et al. (2002) para pacientes humanos com essa afecção, já que não foram localizados relatos com a mesma lesão em tecido mole de animais. $\mathrm{O}$ procedimento realizado foi menos agressivo do que os de cistos ósseos aneurismáticos que se originam de ossos em caninos, tendo em vista que, na maioria das vezes, é necessária a remoção do osso ou parte dele, inclusive com amputações de membros (Nomura e Sato, 1997; Verão et al., 2010). Também como opção terapêutica, Sarierler $e t$ al. 
(2004) e Vignoli et al. (2015) relataram com sucesso a utilização de cimento ósseo para manutenção de membro torácico em cão com cisto ósseo aneurismático, inclusive com o auxílio de tomografia computadorizada durante o procedimento (Vignoli et al., 2015). Já Duval et al. (1995) associaram curetagem e enxerto ósseo esponjoso no tratamento da afecção na tíbia de um cão.

Os diagnósticos diferenciais no histopatológico incluem outras afecções ósseas que contenham células gigantes, como o tumor de células gigantes dos ossos, cisto ósseo simples, displasia fibrosa e variantes de células gigantes do osteossarcoma e granuloma reparativo (Andrade, 2008). Histologicamente, o cisto ósseo aneurismático não vai apresentar as células neoplásicas com características morfológicas malignas de osteossarcoma (Nielsen et al., 2002).

\section{CONCLUSÃO}

O tratamento cirúrgico empregado no cão com cisto ósseo aneurismático em tecido mole foi eficaz, tendo em vista a completa remoção da estrutura e o desaparecimento dos sinais clínicos. $\mathrm{O}$ prognóstico foi muito bom devido à total recuperação do paciente, associada ao caráter benigno da lesão, sem sinais de recidiva em pelo menos 11 meses.

\section{REFERÊNCIAS}

ANDRADE, S.A.F. Tumores ósseos em cães. UNILUS Ensino Pesqui., v.5, p.5-12, 2008.

ASAUMI, J.; KONOUCHI, H.; HISATOMI, M. et al. MR features of aneurysmal bone cyst of the mandible and characteristics distinguishing it from other lesions. Eur. J. Radiol., v.45, p.108$112,2003$.
BARNHART, M.D. Malignant transformation of an aneurysmal bone cyst in a dog. Vet. Surg., v.31, p.519-524, 2002.

BILLER, D.S.; JOHNSON, G.C.; BIRCHARD, S.J.; FINGLAND, R.B. Aneurysmal bone cyst in a rib of a cat. J. Am. Vet. Med. Assoc., v.190, p.1193-1195, 1987.

DOWDLE, S.M.; SPOTSWOOD, T.C.; LAMBRECHTS, N.E.; DUNCAN, N.M. Aneurysmal bone cyst in the distal radius of a dog: diagnostic imaging and surgical treatment. Vet. Comp. Orthop., v.16, p.116, 2003.

DUVAL, J.M.; CHAMBERS, J.N.; NEWELL, S.M. Surgical treatment of an aneurysmal bone cyst in a dog. Vet. Comp. Orthop., v.8, p.48-52, 1995.

NIELSEN, G.P.; FLETCHER, C.D.; SMITH, M.A. et al. Soft tissue aneurysmal bone cyst: a clinicopathologic study of five cases. Am. J. Surg. Pathol., v.26, p.64-69, 2002.

NOMURA, K.; SATO, K. Pelvic aneurysmal bone cyst in a dog. J. Vet. Med. Sci., v.59, p.1027-1030, 1997.

SARIERLER, M.; CULLU, E.; YUREKLY, Y.; BIRINCIOGLU, S. Bone cement treatment for aneurysmal bone cyst in a dog. J. Vet. Med. Sci., v.66, p.1137-1142, 2004.

SILVA, E.D.O; GOMES, A.C.A.; RAIMUNDO, R.C. et al. Cisto ósseo aneurismático: relato de caso e revisão de literatura. Rev. Circ. Traumatol. Buco-MaxiloFac., v.7, p.9-18, 2007.

VERÃO, T.O.; SOUZA, A.I.; BERGAMO, F.M.M. et al. Obstrução urinária por cisto ósseo aneurismático no osso peniano de um cão. Ciênc. Rural, v.40, p.186-189, 2010.

VIGNOLI, M.; STEHLIK, L.; TERRAGNI, R. et al. Computed tomography-guided cementoplasty combined with radiation therapy for an aneurysmal bone cyst in a dog: a case report. Vet. Med., v.60, p.109-114, 20 